\title{
Study on Sport Injuries among College Students in Wuhan
}

\author{
Ying Zhao \\ Department of Physical Education, Wuhan University of Technology, Wuhan, China \\ Email: zhaoying_wh@126.com \\ Received January $14^{\text {th }}, 2013$; revised February $16^{\text {th }}, 2013$; accepted March $1^{\text {st }}, 2013$
}

\begin{abstract}
Copyright (C) 2013 Ying Zhao. This is an open access article distributed under the Creative Commons Attribution License, which permits unrestricted use, distribution, and reproduction in any medium, provided the original work is properly cited.
\end{abstract}

\begin{abstract}
Objective: To investigate the characteristics and the precaution of and reduction of sport injuries among college students in Wuhan, and to provide evidence for the prevention. Methods: Stratified and cluster random sampling method was used to choose 1103 students from a university in Wuhan. A self-designed questionnaire was used to investigate the characteristics of sport injuries among 172 college students who had experienced sport injuries. Results: The incidence of sport injuries among college students in Wuhan was $15.59 \%$. Sport injuries were closely related with sports events, sports technique, physical condition of exerciser, and ground equipment. The incidence of sport injuries was higher in basketball, soccer and physical fitness exercise. Sport injuries were mainly soft tissue damage. The locations of injuries were primary in ankle joint $(56.69 \%)$. Injuries induced by basketball \& soccer were prone to occur in physical education class, while injuries caused by physical fitness exercise were prone to occur in extracurricular activities. Conclusion: The incidence of sport injuries was higher in basketball \& soccer, and sport injuries were prone to occur in physical education class. It was imperative to strengthen the measures of prevention and intervention in college sport injuries.
\end{abstract}

Keywords: College Students; Sport Injuries; Prevention

\section{Introduction}

With the development of Chinese higher education and the increasing improvement of various sports equipment and facilities indoors and outdoors, more and more college students were keen on participating in different sports games, events and competitions. When actively taking part in sports games and events, they were often prone to suffer from injuries such as skin scratches, soft tissue and ankles damage, which greatly spoiled their enthusiasm and confidence in the prospective sports games and activities, on one hand, and on the other hand, influenced their study and life, even brought about lifelong regrets to students. Though this situation has aroused the awareness of higher institutes and PE teachers, we knew, injuries were always accompanied by the sports games. Thus it was necessary to perform a durable preventive and intervention research to avoid sport injuries.

This paper, based on the investigation and analysis of the questionnaire from 1103 college students, with the qualitative and quantitative method, was intended to put forward some suitable suggestions to prevent and intervene sport injuries and arouse the awareness of physical educationists from higher education and institutes to attach more importance to imparting the knowledge of protecting to students when they were working out and performing the sports games.

\section{Methods}

\section{Subjects}

Take 1103 college students of 30 classes out of 2010 and
2011 grades from a certain comprehensive university of Science and Technology of the Ministry of Education in Wuhan as subjects to investigate sport injuries for a period of one year.

\section{Criteria of Sport Injuries}

The criteria of sport injuries included the following situations: 1) the injuries were treated in clinic or hospital; 2) the injuries were processed by oneself or classmates and teachers for emergency.

\section{Quality Control}

Before the formal investigation, the pre-investigation was done on 10 subjects on the spot as in order to guarantee the quality of the survey and unified standard.

\section{Statistical Analysis}

Data was analyzed by SPSS17.0. Descriptive analysis, such as the description of the frequency, rate calculation, 2 tables using $\chi^{2}$ test was used.

\section{Results}

\section{The Sociological Characteristics of Subjects}

Age of the subjects ranged from 19 to 23 years old, the average age was $20.44 \pm 1.22$ years. $34.88 \%$ of the students came from rural areas, $31.98 \%$ of them from towns, $33.14 \%$ of the students from large and medium-sized cities; one child of the family and non-one child accounting of $47 \%$ and $53 \%$. Of the 
1103 college students, 172 suffered from the sport injuries in the past school year. The incidence of total sport injuries was $15.59 \%$. Of which, male students 137 , accounting for 79.65 percent, the female 35 , accounting for $20.35 \%$.

\section{Sport Injuries Caused by Events in College Students}

The survey showed that sport injuries were closely related with sports events. Sport injuries occurred mostly in the three kinds of sport activities, such as basketball, football and physical fitness movement, moreover, the incidence occurred in basketball and football was much higher than that in other sport events. Details were shown in Table 1.

The results of the interviews showed that basketball and football were the most popular sports activities. Competitions on these events were frequently held on a large or small scale by college students. Because these ball games are team activities, which can help cultivate the spirit of teamwork, schools and faculties attach more importance to these. But as ball games was fierce, and male students were aggressive and eager for success, which often leaded to a higher incidence of sport injuries. While the personal items such as table tennis, badminton and martial arts have no direct physical confrontation and the amount of exercise was easy to control, compared with the ball games, sport injuries occurred less frequently.

\section{Classifications and Vulnerable Parts of Sport Injuries in College Students}

We knew different sports activities would result in different sport injuries respectively, also the classification of sport injuries were not identical, until now its uniform criteria had not been settled down.

Referencing to sport injuries classification by Qu Mianyu (2003), combining with the characteristics of college students' sport injuries, sport injuries was classified as four: skin damage, ligament tear, joints dislocation and fracture. Generally speaking, sport injuries were more common in small wounds, more cases like the injuries of skin, muscle, tendon and joint soft tissue so on were likely to happen to college students in sport injuries. From the constitute of sport injuries, the top three are skin damage $(38.95 \%)$, muscle ligament tear or rupture, $(33.14 \%)$ dislocation of the joint $(24.42 \%)$. Concussion of the brain and visceral rupture are less to happen to students. Details were listed in Table 2.

The results showed that ankle injuries were the most common accounting for $56.69 \%$ of all sport injuries, followed by the knee, accounting for $25.54 \%$, and then hands, head and

Table 1.

Sport injuries of college students caused by different events.

\begin{tabular}{ccc}
\hline Events & N & Percentage (\%) \\
\hline Basketball & 81 & 47.09 \\
Football & 49 & 28.49 \\
Physical fitness & 27 & 15.70 \\
Volleyball & 6 & 3.49 \\
Others & 9 & 5.23 \\
Total & 172 & 100 \\
\hline
\end{tabular}

other parts are on the third rank, accounting for $17.87 \%$.

\section{Occurrence Time of Sport Injuries}

The results showed that sport injuries of college students occurred more in extracurricular activities, the percentage of extracurricular activities injuries was higher than that of sports activities in physical education class organized by teachers. Details were listed in Table 3.

\section{Causes of Sport Injuries}

The results showed that the causes of the sport injuries were various. Sport injuries were closely related with sports events, sports technique, physical condition of exerciser, and ground equipment. In this study, the main causes were body collision, physical fatigue, poor quality, and lack of the self-protection awareness, insufficient preparation, wrong moving and so on. Details were listed in Table 4.

Table 2.

Classifications of sport injuries in college students.

\begin{tabular}{lcc}
\hline Classifications of sport injuries & N & Percentage (\%) \\
\hline Skin damage & 67 & 38.95 \\
Muscle ligament tear or rupture & 57 & 33.14 \\
Joint dislocation & 42 & 24.42 \\
Fracture & 2 & 1.16 \\
Others & 4 & 2.33 \\
Total & 172 & 100 \\
\hline
\end{tabular}

Table 3.

The occurrence time of sport injuries in college students.

\begin{tabular}{lcc}
\hline Occurrence time of sport injuries & $\mathrm{N}$ & Percentage (\%) \\
\hline Extracurricular activities & 125 & 72.67 \\
Physical education & 37 & 21.51 \\
Sports competitions & 7 & 4.07 \\
Others & 3 & 1.74 \\
Total & 172 & 100 \\
\hline
\end{tabular}

Table 4. Causes of sport injuries in college students.

\begin{tabular}{lcc}
\hline Causes of sport injuries & $\mathrm{N}$ & $\%$ \\
\hline Body collision & 45 & 26.16 \\
Fatigue/poor quality & 38 & 22.09 \\
Lack of the self-protection awareness & 36 & 20.94 \\
Insufficient preparation & 36 & 20.93 \\
Incorrect technical movements & 37 & 15.70 \\
Overload of exercise & 12 & 6.98 \\
Psychological factors & 11 & 6.40 \\
Ground equipment & 4 & 2.33 \\
Total & 172 & 100 \\
\hline
\end{tabular}




\section{Characteristics of the Top Three Sport Events of Sport Injuries}

The results showed that sport injuries in basketball, football and the physical quality sports activities were different. The difference of occurrence time in these three events was statistically significant $(p<0.05)$. e.g., the incidence of sport injuries in basketball and football occurred mainly in the physical education classes, while the incidence of that in physical fitness exercise often happened in extracurricular activities. As to vulnerable parts, injuries types and insufficient preparation, the differences were not statistically significant $(p>0.05)$. Details were listed in Table 5.

\section{Discussion}

Sport injuries not only brought misfortune and suffering to the students and parents, but also affected the normal teaching order and plan of physical education class. From this investigation, the incidence of sport injuries of college students in $\mathrm{Wu}-$ han city was $15.59 \%$, which is lower than that of other two cities of Guangzhou and Hefei (Bai, Zhang, \& Chen, 2011; Chen, Liu, \& Ye, 2007).

In this investigation, sport injuries in college students occurred mainly in basketball, football and physical fitness exercise, and the injuries rate was far higher than that of other sports, which was in keeping wit to other researches' (Bai, Zhang, \& Chen, 2011; Chen, Liu, \& Ye, 2007). These events were aerobic metabolism item of improvement heart-lung capability endurance that was keeping long time, active strength high. It was especially more physical in basketball and football and the pace was faster, demanding good physical qualities. Playing basketball needed complex and changeable techniques, strong adaptability. Players were frequently constrained by the opponent during the confrontation, causing in-coordination and an error action, contrary to the principles of biomechanics. All of which were apt to cause injuries occurred. The characteristics of being difficult and violent confrontation and trans.pts fast increased the risks of damage. Movement unskilled, the use of unreasonable, in violation of the rules, rough play wound

Table 5.

Occurrence time of sport injuries in basketball, football and physical fitness exercise.

\begin{tabular}{|c|c|c|c|}
\hline \multirow[b]{2}{*}{$\begin{array}{l}\text { Kinds of } \\
\text { exercise }\end{array}$} & \multicolumn{3}{|c|}{ Time of occurrence } \\
\hline & $\begin{array}{c}\text { Extracurricular activities } \\
\qquad \mathrm{n}(\%)\end{array}$ & $\begin{array}{c}\text { Physical educated } \\
\text { n (\%) }\end{array}$ & $\begin{array}{l}\text { Others } \\
\mathrm{n}(\%)\end{array}$ \\
\hline Basketball & $18(22.22)$ & $61(75.31)$ & $2(2.47)$ \\
\hline Football & $4(8.16)$ & $41(83.67)$ & $4(8.16)$ \\
\hline $\begin{array}{l}\text { Physical fitness } \\
\text { exercise }\end{array}$ & $12(44.44)$ & $11(40.74)$ & $4(24.81)$ \\
\hline \multicolumn{4}{|c|}{$\chi^{2}=32.970, p=0.000$} \\
\hline
\end{tabular}

increase opportunities for injuries. It was found that fatigue was one of the risk factors of sport injuries. The proportion that students playing ball more than 1.5 hours was much higher than those less than 1.5 hours. Therefore, it was recommended that the time not be too long, and not exceed 80 minutes.

Particularly, the results showed that college students were prone to be injured in basketball, football teaching class, and the incidence of injuries was higher than that in extracurricular activities, which should arouse the attention of the PE teachers. Therefore, teachers should consider the possibilities of all kinds of unexpected events in advance before PE class, and take some preventive measures. Also teachers should enhance their sense of responsibility. At the same time, ability to protect themselves during movement should be focused among students. It was found that capacity of self-protection was closely related to injuries accident (Wang \& Yu, 2005). Presently, college sports work both "teaching" and "learning" didn't pay enough attention to the ability of "self-protection". So this situation should be adjusted immediately to avoid the occurrence of damage.

Although the survey results showed that items such as table tennis, tennis, badminton, and martial arts almost no damage occurs, it did not mean these items would not cause sport injuries. In practical work, we still have to be vigilant, pay attention to the prevention of injuries occurred.

\section{Recommendations}

The sport of basketball and football was popular in universities. And the incidences occurred in these two events were much higher than that in other sport events, which was not only related with technical characteristic, but also with poor physical fitness and weak awareness of self-protection. So prevention of sport injuries was a long-term task in the future.

College students are prone to be injured in basketball, football teaching class, and the incidence of injuries was higher than that in extracurricular activities, which should arouse the attention of the PE teachers. Teachers should enhance their sense of responsibility. College sports work both "teaching" and "learning" didn't pay enough attention to the ability of "self-protection".

\section{REFERENCES}

Bai, W. D., Zhang, Y., \& Chen, F. (2011). Analysis of students' movement injuries and its influencing factors in Guangzhou University. Chinese Journal of School Health, 32, 1346-1350.

Chen, X. M., Liu, X., \& Ye, D. Q. (2007). Epidemiological survey of college students' sport injuries of two universities in Hefei. Chinese Journal of School Health, 28, 536-537.

Qu, M. Y. (2003). Sports medicine (3rd ed.). Beijing: Peking University Medical Press.

Wang, J. J., \& Yu, D. S. (2005). Research of college students' selfprotection development in some colleges and universities in Beijing. Journal of Beijing Sports University, 28, 681-683. 